\title{
NOTE
}

\section{Sex attractant in the marine insect Trochopus plumbeus (Heteroptera: Veliidae): a preliminary report}

\author{
Lanna Cheng ${ }^{1, *}$, Vassilios Roussis ${ }^{2}$ \\ 'Scripps Institution of Oceanography, University of California, San Diego, California 92093-0202, USA \\ ${ }^{2}$ Department of Pharmacognosy, University of Athens, Panepistimiopolis-Zografou, GR-157 71 Athens, Greece
}

\begin{abstract}
We present evidence of sex-attracting substances produced by males of the marine insect Trochopus plumbeus. This small veliid is widely distributed in the Caribbean. Large numbers were found in the mangrove areas of several islands in the Bahamas. Field assays using live insects and extracts demonstrated that females were highly attracted to males and male extracts, but not the opposite. Gas chromatography-mass spectrometry analyses of extracts from both males and females revealed the presence of a series of aldehydes and long-chain aliphatic acids that are insoluble in water, some of which could possibly act as surface-dispersible semiochemicals.
\end{abstract}

KEY WORDS; Sex attractant - Pheromone - Sexual communication. Mangrove - Marine insect - Caribbean - Trochopus plumbeus - Veliidae

Trochopus is a neotropical genus of veliids confined to Central and South American coasts. There are 5 known species: plumbeus (Uhler), salinus (Champion), ephydros Drake \& van Doesburg, arcuatus Polhemus \& Manzano, and columbianus Polhemus \& Manzano (Drake \& van Doesburg 1966, Polhemus \& Manzano 1992). T. plumbeus, the most widely distributed species, is found from the Florida coast (USA) to most of the Caribbean islands (Andersen \& Polhemus 1976). The other species are much more restricted in their distributions. These veliids are found in habitats commonly occupied by nearshore Halobates (Gerridae), another semi-aquatic heteropteran, in the Indo-Pacific. Although the pelagic Halobates micans Eschscholtz is common in tropical Atlantic waters, coastal Halobates species are completely absent from the Caribbean (Cheng 1989).

Adults of Trochopus plumbeus are small (males about $1.5 \mathrm{~mm}$; females $3.0 \mathrm{~mm}$ ) and completely wing-

\footnotetext{
•E-mail: Icheng@ucsd.edu
}

less, probably an adaptation to their marine habitat (Andersen \& Polhemus 1976). They are predators and feed on other small insects or invertebrates caught on the water surface (L. Cheng pers, obs.). How these insects find one another and mate in their ever-changing marine environment was not known. During a research expedition to the Bahamas in August 1995 we found $T$. plumbeus at several islands, sometimes in great abundance. The availability of large numbers at Long Island provided a rare opportunity for us to perform field experiments and to collect sufficient specimens for chemical analyses in the laboratory. We report here the first evidence for sex-attracting substances produced by males of $T$. plumbeus.

Methods. We used a $10 \mathrm{~cm}$ diameter plastic strainer with $1 \mathrm{~mm}$ mesh for catching the insects. Several hundred adults were captured at Joe Sound, Long Island and brought back to the research vessel. They were sorted by sex. Groups of about 50 males or females were kept in separate 5 l polypropylene containers filled with clean seawater, placed on a bench in a shipboard laboratory kept at $25^{\circ} \mathrm{C}$, and illuminated with fluorescent lights. The specimens were used for biological observations, chemical extractions or field experiments as needed.

To find out whether chemical communication may be employed by Trochopus plumbeus we carried out a few simple experiments (for details see below). We placed groups of 5 males or females in separate $1 \mathrm{l}$ beakers connected at water level by a length of tubing which allowed passage of insects from one beaker to the other. We observed females moving to beakers containing males or male extracts, but not vice versa $(n=6)$. Subsequent experiments were carried out in the field using insects as well as extracts.

For field bioassays 10 insects of one sex were placed on clean tissue paper (Kimwipes) and allowed to clean 
and dry themselves. They were then transferred to a clean glass vial with $5 \mathrm{ml}$ of dichloromethane and extracted for $2 \mathrm{~h}$ or left in the refrigerator overnight. The extracts were applied to strips of filter paper $(2 x$ $5 \mathrm{~cm}$ ) and air-dried. Each test strip received an extract from 10 insects. Since preliminary test-runs $(n=4)$ gave similar results for test strips with either $2 \mathrm{~h}$ or overnight extracts, all subsequent bioassays were carried out using 2 h extracts.

Bioassays to test for chemotropism were carried out in situ, on sandy shores at Joe Sound on 2 successive calm, windless days at about noon (to avoid shadowing effects). The experimental set-up consisted of 2 polypropylene beakers (1 l) connected by a horizontal channel of plastic (Tygon) tubing $(10 \mathrm{~cm}$ long, $1.5 \mathrm{~cm}$ diameter). Fresh seawater was poured into the beakers until the water level half-filled the connecting tubing, where a flat, undisturbed water surface was maintained. For each bioassay, 5 insects of one sex were introduced into one beaker and a test strip into the other, simultaneously. Movements of insects were observed, and numbers in each beaker were recorded every $30 \mathrm{~s}$. Each experiment was concluded at the end of 3 min. Beakers and tubing were washed with a mild detergent and rinsed thoroughly with seawater between experiments, and beakers containing insects or extracts were reversed after each experiment. A total of 14 experiments were carried out (see Table 1).

Chromatographic analyses of the extracts were carried out in the Laboratory of Pharmacognosy, University of Athens, Greece. For chemical analyses we used 3 batches of samples, each composed of 20 males and

Table 1. Trochopus plumbeus. Sex of insect or extract and number of insects in release and extract beakers at the end of each experimental period ( $3 \mathrm{~min}$ ). (Contingency table chisquared test, $\chi^{2}=46.75, \mathrm{df}=3, \mathrm{p} \ll 0.001$; Conover 1980)

\begin{tabular}{|lccc|}
\hline $\begin{array}{l}\text { Sex of } \\
\text { test } \\
\text { insects }\end{array}$ & $\begin{array}{c}\text { Source } \\
\text { of } \\
\text { extract }\end{array}$ & $\begin{array}{c}\text { No. of insects } \\
\text { in release } \\
\text { beaker }\end{array}$ & $\begin{array}{c}\text { No. of insects } \\
\text { in extract } \\
\text { beaker }\end{array}$ \\
\hline Female & Male & 0 & 5 \\
Male & Female & 0 & 4 \\
& & 4 & 5 \\
Female & Female & 5 & 1 \\
& & 5 & 0 \\
Male & & 5 & 0 \\
& & 5 & 0 \\
& & 5 & 0 \\
& & 5 & 1 \\
& & 5 & 0 \\
& & 5 & 0 \\
\hline
\end{tabular}

20 females extracted separately in $2 \mathrm{ml}$ of $80 \%$ dichloromethane $+20 \%$ methanol for $2 \mathrm{~h}$. The insects were subsequently removed and the filtrates concentrated by evaporating most of the solvents at atmospheric pressure, using a 'vigreux' column as an extra precaution in order not to lose volatile metabolites The extracts were then analysed by gas chromatography (Hewlett Packard 6890 with an on-column injector and a flame ionization detector, with $\mathrm{He}$ as the carrier gas) coupled with mass spectrometry (Hewlett Packard 5973). Identification of the chemical constituents was based on comparisons of their retention times (Rt values) and mass spectra with those of authentic samples and/or from the NIST/NBS and Wiley databases.

Results. During the Bahamas expedition Trochopus plumbeus was found at the following islands: Grand Bahama (Sweetings Key), Long, Crooked (French Wells), Acklins, and Eleuthera (Eleuthera Point), but not on Lee Stocking, Great Exuma, San Salvador or Nassau. The insects were associated with coastal vegetation and were absent along sandy or rocky shores. They were most abundant where there were extensive mangroves (Rhizophora or Avicennia). At Joe Sound, Long Island, T. plumbeus occurred in dense patches floating among roots of the black mangrove Avicennia germinans. Many patches measured 20 to $30 \mathrm{~cm}$ across and consisted of several hundred adults or sub-adults, either single or in pairs. When disturbed they dispersed but re-assembled again within minutes. We found nymphs of all stages as well as adults and mating pairs. Nymphs commonly occurred in the shade under trees, often among mangrove roots. Mating pairs formed dense aggregations, similar to those observed in Halobates robustus Barber in the Galàpagos Islands (Birch et al. 1979). During mating the much smaller male clasps the female with his front legs and is carried by her while she moves around or feeds. Pairs that we kept in tanks on board ship remained in copula for several days and did not separate even when netted and transferred from bucket to vial, or into $70 \%$ ethanol. Such prolonged pairing could be an adaptation for insects living in a habitat subject to turbulence of waves and tides, which may prevent the sexes from pairing and retaining contact. It could also be a form of post-copulatory mate-guarding, which has been observed especially among insects in which the males are much smaller than the females (Alcock 1994), e.g in several gerrids (Spence \& Andersen 1994) and a Microvelia (Travers \& Sih 1991).

Although during field experiments the number of Trochopus plumbeus in each beaker was scored after every $30 \mathrm{~s}$, we present in Table 1 only the final counts at the end of $3 \mathrm{~min}$ Some insects were observed to move between the 2 beakers a number of times, but after 1 or 2 min there was little or no fur ther movement 
between beakers. The most dramatic movements were observed in bioassays involving female insects and male extracts. Almost all the females moved over to the male-extract beaker within the first $30 \mathrm{~s}$, and remained there until the end of the experimental period. It was evident that female insects were significantly attracted to male extracts, and there was no similar attraction between insects and extracts in any other combinations ( $p \ll 0.001$ ). Since the air-dried extract strips were placed on the water surface it is possible that the constituents of the extract could be surface-dispersible rather than airborne.

We were able to identify 80.05 and $83.29 \%$ of the total lipid constituents of the male and female extracts (approx. $40 \mathrm{ng}$ male ${ }^{-1}, 28 \mathrm{ng}$ female $^{-1}$ ) of Trochopus plumbeus respectively (Table 2 ). The majority comprised linear-chain medium-sized (6 to $10 \mathrm{C}$ ) aldehydes, and a series of longer-chain ( 14 to $18 \mathrm{C}$ ) acids and acid esters. Most of the identified compounds are relatively insoluble in water but bear a polar functional group that may promote their dispersion over a water film. They could thus act as surface 'messengers'. Although no obvious qualitative differences were found between the chemical compositions of the extracts from the 2 sexes of $T$. plumbeus, there were significant quantitative differences. The male extract had much higher contents of hexanal, actanal, 2-Edecenal, 2,4-(E,E)-decadienal, and especially the methyl ester of octadecenoic acid. This implies that, if the specific sex attractant is one or more of these compounds, the males may be capable of selectively synthesizing and releasing them. It is also quite possible that the active chemical is one of the unidentified compounds or there is an active blend of chemicals.

Since female Trochopus plumbeus were observed to move to the beaker containing male extract within 2 to 3 s after its application on the water, we speculate that the dispersion rate of the attractant could be rather high. Rough calculations based on our experimental setup (length of connecting tubing and time taken for insects to move between beakers) indicated that the diffusion rate of the attractant could be as high as $10 \mathrm{~cm} \mathrm{~s}^{-1}$. Unfortunately we had no opportunity to carry out more experiments during our short expedition.

Discussion. Sex pheromones are probably the most widely studied of insect semiochemicals. Most are airborne, produced by the female, and may be detectable by males several $\mathrm{km}$ downwind from the source (Murlis et al. 1992). Male-produced pheromones are rare and not all are sex-specific, attracting females as well as males, and sometimes acting even as aggregation pheromones (Landolt 1997). Many arthropods are also known to adapt the same chemicals to serve separate functions, e.g. in sex attraction, defence, alarm or aggregation (Blum 1996). The majority of identified insect sex pheromones comprise several long-chain unsaturated alcohols, acetates, aldehydes or carboxylic acids. Each species may blend these compounds in various proportions to produce a specific sex pheromone (Roelofs 1995). Hexadecanoic acid, which constitutes some $30 \%$ of the Trochopus plumbeus extracts, was previously identified as a component of the male sex pheromone of the dung beetle Khefer lamarcki

Table 2. Trochopus plumbeus. Chemical compositions of male and female extracts (mean $\% \pm S E, n=3$ )

\begin{tabular}{|c|c|c|c|}
\hline & $\begin{array}{c}\text { Male } \\
(\%)\end{array}$ & $\begin{array}{c}\text { Female } \\
{[\%]}\end{array}$ & $\begin{array}{l}\text { Ratio } \\
M / F\end{array}$ \\
\hline Hexanal & $0.07 \pm 0.03$ & $0.01 \pm 0.01$ & 7.0 \\
\hline Octanal & $0.08 \pm 0.02$ & $0.02 \pm 0.02$ & 4.0 \\
\hline 2-E-Decenal & $0.64 \pm 0.08$ & $0.08 \pm 0.03$ & 6.0 \\
\hline 2,4-(E,Z)-Decadienal & $0.15 \pm 0.04$ & $0.34 \pm 0.05$ & 0.4 \\
\hline 2,4-(E,E)-Decadienal & $0.22 \pm 0.04$ & $0.05 \pm 0.01$ & 4.4 \\
\hline Hexadecane & $1.72 \pm 0.20$ & $2.60 \pm 0.16$ & 0.7 \\
\hline Tetradecanoic acid & $0.77 \pm 0.11$ & $0.47 \pm 0.01$ & 1.6 \\
\hline 1-Hexadecanol & $9.15 \pm 0.23$ & $9.71 \pm 0.49$ & 0.9 \\
\hline Hexadecanoic acid, methyl ester & $2.12 \pm 0.04$ & $1.03 \pm 0.04$ & 2.1 \\
\hline Hexadecanoic acid & $31.44 \pm 0.16$ & $30.29 \pm 2.19$ & 1.0 \\
\hline 9-Z-Octadecen-1-ol & $6.63 \pm 0.17$ & $10.65 \pm 0.88$ & 0.6 \\
\hline 9-Z-Octadecenoic acid, methyl ester & $7.53 \pm 0.27$ & $3.68 \pm 0.22$ & 2.0 \\
\hline Octadecenoic acid, methyl ester & $0.79 \pm 0.07$ & $0.04 \pm 0.01$ & 19.8 \\
\hline 9-Z-Octadecanoic acid & $7.82 \pm 0.80$ & $17.07 \pm 0.79$ & 0.5 \\
\hline Octadecanoic acid & $10.15 \pm 0.76$ & $6.83 \pm 0.58$ & 1.5 \\
\hline Pentatriacontane & $0.87 \pm 0.01$ & $0.41 \pm 0.06$ & 2.1 \\
\hline Total & $80.05 \pm 1.61$ & $83.29 \pm 3.63$ & - \\
\hline High-molecular-weight hydrocarbons & $13.35 \pm 0.94$ & $6.41 \pm 0.94$ & - \\
\hline
\end{tabular}


Macleay (although it did not attract any females in baited traps; Mayer \& McLaughlin 1990). However, this compound was found in equal amounts in both sexes of $T$. plumbeus, indicating that it is not likely to be a component of the male-produced pheromone. Among the other compounds identified in our extracts, octanal has been found to be a minor component of the male hair-pencil pheromone of Amauris ochlea (Boisduval) (Lepidoptera: Danaidae) whereas hexanal, hexadecane, and 1-hexadecanol were found in female attractants (Mayer \& McLaughlin. 1990).

Very few pheromone systems have been identified in the Hemiptera (Aldrich 1988, 1995, Mayer \& McLaughlin 1990) and none has been demonstrated in any aquatic species (Andersen 1982). Several species of Gerridae are known to use surface ripples for sexual communication (Wilcox \& Spence 1986, Spence \& Andersen 1994), and this system may also be used by the Veliidae (Polhemus 1990) to which Trochopus belongs. However, the use of surface ripples has never been demonstrated as a means of sexual communication in any marine Heteroptera.

For marine insects like Trochopus plumbeus, which lives exclusively in a 2-dimensional habitat at the seaair interface, one could hypothesise that any effective and economical chemical attractant would have to be readily dispersible over a surface film. At the sea surface, an airborne attractant might be too readily winddispersed and difficult to locate, thus unnecessarily wasteful to synthesize. A surface-dispersible agent would be preferable, presumably operating most effectively on still waters during periods when the sea is calm. We do not know whether there are evolutionary or behavioral advantage(s) for $T$. plumbeus to have a male-rather than a female-produced pheromone.

Although sex attractants have been demonstated in many marine invertebrates, only a few have been isolated and identified chemically (Harder et al. 1996). We believe this is the first report of a sex-attracting substance produced by the males of an aquatic insect to attract females. Since we are still unable to rear Trochopus plumbeus in the laboratory and our attempt to bring live specimens back to land-based laboratories for further research was not successful, bioassays with chromatographic fractions of the extracts or with the reported compounds will have to be conducted in the field before the chemical nature of the pheromone(s) can be fully defined.

Acknon ledgements. We are grateful to Dr William H. Fenical, chief scientist of the Bahamas Expedition (under NSF Grant CHE93-22776), for inviting us to participate; the captain, crew and fellow scientists of the RV 'Seward Johnson' for their help in various ways; Dr Ralph A. Lewin for assistance in the field; and Ms C. Karapati for assistance with the gas chromato- graphic analyses. We also thank Drs Nils M. Andersen (Denmark), Martin C. Birch (UK), Wolf Blanckenhorn (Switzerland), Nancy Lo (USA), John T Polhemus (USA), Julio Rojas (UK), Tristram Wyatt (UK) and anonymous reviewers for constructive criticisms and helpful comments. This work was partially supported by the U.S. Office of Naval Research (N10014-95-1-0142 to L.C.).

\section{LITERATURE CITED}

Alcock J (1994) Postınsemination associations between males and females in insects: the mate-guarding hypothesis. Annu Rev Entomol 39:1-21

Aldrich JR (1988) Chemical ecology of the Heteroptera. Annu Rev Entomol 33:211-238

Aldrich JR (1995) Chemical communication in the true bugs and parasitoid exploitation. In: Cardé RT, Bell WJ (eds) Chemical ecology of insects 2. Chapman and Hall, New York, p 318-363

Andersen NM (1982) The semiaquatic bugs (Heteroptera. Gerromorpha). Entomonograph 3:1-145

Andersen NM, Polhemus JT (1976) Water-striders (Hemiptera: Gerridae, Veliidae, etc.). In: Cheng L (ed) Marine insects. North Holland, Amsterdam, p 187-224

Birch MC, Cheng L, Treherne JE (1979) Distribution and envronmental synchronization of the marine insect, Halobates robustus, in the Galàpagos Islands. Proc R Soc Lond B 206:33-52

Blum MS (1996) Semiochemical parsimony in the Arthropoda. Annu Rev Entomol 41:353-374

Cheng L (1989) Biogeography and phylogeny of the seaskater Halobates. Chinese J Ocean Limnol 7:233-239

Conover WJ (1980) Practical nonparametric statistics. John Wiley \& Sons. New York

Drake CJ, van Doesburg P Jr (1966) Water-striders of the American genus Trochopus (Hemiptera: Velidae). Stud Fauna Suriname Other Guyanas 8:65-76

Harder T, Beckmann K, Müller CT (1996) Marine gameterelease pheromones. Nature 382:214

Landolt PJ (1997) Sex attractant and aggregation pheromones of male phytophagous insects. Am Entomol 43(1):12-22

Mayer MS, McLaughlin JR (1990) Insect pheromones and sex attractants. CRC Press, Boca Raton

Murlis J, Elkinton JS, Cardé RT (1992) Odor plumes and how insects use them. Annu Rev Entomol 37:505-532

Polhemus JT (1990) Surface wave communication in water striders: field observations of unreported taxa (Gerridae, Veliidae: Heteroptera). J NY Entomol Soc 98:383-384

Polhemus JT, Manzano MR (1992) Marine Heteropera of the eastern tropical Pacific (Gelastrocoridae, Gerridae, Mesoveljidae, Saldidae, Veliidae). In: Quintero D, Aiello A (eds) Insects of Panama and Mesoamerica. Oxford University Press, Oxford, p 302-320

Roelofs WL (1995) The chemistry of sex attraction. In: Eisner T, Meinwald J (eds) Chemical ecology. National Academy Press, Washington, DC, p 103-117

Spence JR, Andersen NM (1994) Biology of water striders: interactions between systematics and ecology. Annu Rev Entomol 39:101-128

Travers EE, Sih A (1991) The influence of starvation and predators on the mating behavior of a semiaquatic insect Ecology 72:2123-2236

Wilcox RS, Spence JR \{1986\} The mating system of two hybridizing species of water striders (Gerridae). I. Ripple signal functions. Behav Ecol Sociobiol 19: 79-85

Submitted: March 30, 1998, Accepted: June 22, 1998

Proofs recelved from author(s): August 13, 1998 